\title{
Identification, Characterization, and Evaluation of Novel Stripe Rust-Resistant Wheat-Thinopyrum intermedium Chromosome Translocation Lines
}

\author{
Xingwei Zheng, ${ }^{1}$ Caiguo Tang, ${ }^{1}$ Ran Han, ${ }^{2}$ Jiajia Zhao, ${ }^{1}$ Ling Qiao, ${ }^{1}$ Shuwei Zhang, ${ }^{3}$ Linyi Qiao, ${ }^{3}$ Chuan Ge, ${ }^{3}$ Jun Zheng, ${ }^{1, \dagger}$ \\ and Cheng $\mathrm{Liu}^{2, \dagger}$ \\ ${ }^{1}$ Institute of Wheat Research, Shanxi Agricultural University, Linfen 041000, China \\ ${ }^{2}$ Crop Research Institute, Shandong Academy of Agricultural Sciences/Key Laboratory of Wheat Biology and Genetic Improve- \\ ment in the North Yellow \& Huai River Valley, Ministry of Agriculture/National Engineering Laboratory for Wheat \& Maize, \\ Jinan 250100, China \\ ${ }^{3}$ Institute of Crop Science, Shanxi Agricultural University, Taiyuan 030031, China
}

\begin{abstract}
Stripe rust is an important disease in wheat, and development of genetic resistance in cultivars is an effective approach to control the disease. Wild species of wheat, such as Thinopyrum intermedium, are an excellent gene source for wheat improvement. In this study, two stripe rustresistant wheat-Th. intermedium chromosome translocation lines, $\mathrm{CH} 4131$ and $\mathrm{CH} 4132$, were characterized by cytogenetic and pathological methods. The introgressed chromosome fragment was tagged using amplified fragment-length polymorphism-derived sequencecharacterized amplified region (SCAR) markers and intron targeting

lines, forming a configuration of T3Ai-1BS.1BL. The two translocation lines were resistant to stripe rust, and the resistance gene, temporarily designated $\mathrm{YrCH}-1 \mathrm{BS}$, was likely derived from Th. intermedium. The translocated chromosome fragments have no genetic linkage drag to agronomic performance. The grain quality indexes of these two translocations were higher than local wheat varieties. Therefore, $\mathrm{CH} 4131$ and $\mathrm{CH} 4132$ could be used as potential gene sources in wheat improvement programs. The SCAR markers are useful to select stripe rust resistance from $T h$. intermedium.
\end{abstract} markers, indicating that $\mathrm{CH} 4131$ and $\mathrm{CH} 4132$ both possess a homologous group 3 chromatin of Th. intermedium. Genomic in situ hybridization results suggested that a very small $T h$. intermedium chromosome segment was translocated to the terminal region of wheat 1BS for both
Keywords: cereals and grains, cultivar/resistance, disease management, field crops, fungi, genomic in situ hybridization, stripe rust, Thinopyrum intermedium
Crop diseases threaten global food security. The genetic improvement of disease resistance greatly impacts the improvement of crop yield. Stripe rust, caused by Puccinia striiformis f. sp. tritici Erikss (Pst), is one of the most devastating diseases of wheat (Triticum aestivum L). Statistical data showed that the area covered by the disease was 4.00 to 5.34 million ha per year in China, and the yield loss was estimated within the range of 10 to $20 \%$ and up to $30 \%$ in the years with serious occurrence (Chen 2005; Wellings 2011). More virulent and aggressive $P$ st races that began to appear around the year 2000 have spread rapidly over most of the wheat-growing regions of the world, causing significant yield losses (Hovmøller et al. 2008, 2016). In 2002, 2003, and 2009, wheat yield losses in China were up to $13.0,9.8$, and 8.1 million metric tons, respectively (Bai et al.

${ }^{\dagger}$ Corresponding authors: J. Zheng; zhengjun@ sxagri.ac.cn, and C. Liu; 1ch6688407@163.com

X. Zheng, C. Tang, and R. Han contributed equally to this work.

Funding: This work was supported by National Key Research and Development Program of China grant 2017YFD0100600, Research Fund for Taishan Scholar grant tsqn201812123, Natural Science Foundation of Shandong Province grant ZR2017MC004, Shanxi Province Applied Basic Research Program grants 201803D421021 and 201605D151002, and Agricultural Science Research of Shanxi Agricultural University grant YCX2018413.

*The $\boldsymbol{e}$-Xtra logo stands for "electronic extra" and indicates that three supplementary figures, two supplementary tables and one supplementary file are published online.

The author(s) declare no conflict of interest.

Accepted for publication 11 September 2019

(c) 2020 The American Phytopathological Society
2014; Zhang et al. 2017a, b). The utilization of resistance genes is considered an economical and effective approach to control wheat diseases. Presently, $>80$ stripe rust resistance genes have been permanently named (McIntosh et al. 2016, 2017, 2018; Wu et al. 2018a). However, the rapid appearance of new virulent $P s t$ races often leads to loss of effectiveness and necessitates searches for new sources of resistance. Therefore, there is a need to discover new stripe rust resistance genes to broaden the wheat gene pool for breeding stripe rustresistant wheat cultivars.

Introducing disease resistance genes from wheat-alien species into wheat through chromosome engineering is an important method in achieving wheat resistance diversity (Brown 2015). Some important disease resistance genes have already been transferred from alien species to wheat, such as $\operatorname{Yr} 8, \operatorname{Yr} 17, \operatorname{Pm} 12$, and $P m 13$ from the genus Aegiliops (Cenci et al. 1999; Chen and Zhao 2007; Robert et al. 1999; Song et al. 2007); $Y r 9, P m 8, P m 7, P m 17$, and $P m 20$ from the genus Secale (Huang and Röder 2004; Hurni et al. 2013; Mago et al. 2005); and Pm21 from the genus Dasypyrum (Liu et al. 1999). Wheat-Thinopyrum translocations T3DS.3DL-3Ae\#1L (Agent), T6AS.6AL6Ae\#1L (K2046), and T7DS.7DL-7Ae\#1L (Agatha); wheat-Secale translocations T1BL.1R\#2S (Aurora and Kavkaz) and T1AL.1R\#2S (Amigo); and wheat-Dasypyrum translocation T6AL.6V\#1S (KS04WGRC48) have made important contributions to both breeding disease-resistant wheat cultivars and increasing yield (Friebe et al. 1994; Wetzel and Rayburn 2000; Xie et al. 2012). However, most wheat-alien species chromosome translocations cannot be used directly in wheat breeding programs owing to genetic drag. Therefore, creating and identifying small chromosome segment translocations in wheat-alien species have become key research topics, because they could be used to overcome this disadvantage.

Thinopyrum intermedium $\left(2 n=6 x=42, \mathrm{E}^{\mathrm{e}} \mathrm{E}^{\mathrm{e}} \mathrm{E}^{\mathrm{b}} \mathrm{E}^{\mathrm{b}} \mathrm{StSt}\right)$ possesses many agronomically useful genes and is one of the most successfully used species in wheat breeding (Friebe et al. 1994; Li et al. 2016). Many examples have shown that $T$. intermedium chromosomes could be easily exchanged and recombined with wheat chromosomes using 
chromosome engineering inducement (Lang et al. 2018; Liu et al. 2011a, b, 2013a, b; Tang et al. 2014; Xin et al. 2001; Zhan et al. 2015). Therefore, transfer of useful genes from Th. intermedium into wheat through creating wheat-Th. intermedium chromosome recombinants is feasible. In this study, two noncompensating wheat-Th. intermedium small chromosome segment translocations of T3Ai-1BS.1BL were identified from progenies of a complex cross involving four common wheat varieties and a Th. intermedium line using molecular cytogenetic methods. The stripe rust resistance, agronomical traits, and grain quality of both lines were investigated. Both lines were highly resistant to stripe rust and had no negative effect on agronomical traits and quality. Therefore, both translocation lines are useful materials for wheat breeding programs.

\section{Materials and Methods}

Plant material. Materials used in this study included four $\mathrm{BC}_{3} \mathrm{~F}_{6}$ translocation lines, $\mathrm{CH} 4131$ to $\mathrm{CH} 4134$, that were derived from the complex cross Chinese Spring (CS)/Z1141//Taichung29 (TC29)///PH82-2-2////3*Shan 225. Z1141 is a genotype of Th. intermedium $\left(2 n=6 x=42, \mathrm{E}^{e} \mathrm{E}^{\mathrm{e}} \mathrm{E}^{\mathrm{b}} \mathrm{E}^{\mathrm{b}} \mathrm{StSt}\right)$. PH82-2-2 and Shan 225 are a breeding line and a cultivar, respectively, of common wheat with good end use qualities. TC29 is a breeding line from Sichuan province. This study also included three Th. intermediumrelated wild species, Thinopyrum elongatum PI98526 $(2 n=2 x=$ $\left.14, \mathrm{E}^{\mathrm{e}} \mathrm{E}^{\mathrm{e}}\right)$, Thinopyrum bessarabicum PI531712 $\left(2 n=2 x=14, \mathrm{E}^{\mathrm{b}} \mathrm{E}^{\mathrm{b}}\right)$, and Pseudoroegneria strigosa PI313960 $(2 n=2 x=14$, StSt $)$, for comparison; cultivar Mingxian169 (MX169) is as a susceptible line to stripe rust, Zhongyou9507 is as a positive control with known

Table 1. Sequences of amplified fragment-length polymorphism adapters and primers used in this research

\begin{tabular}{ll}
\hline & \multicolumn{1}{c}{ Sequence $\left(\mathbf{5}^{\prime} \mathbf{- 3}^{\prime}\right)$} \\
\hline Adaptors $^{\mathrm{z}}$ & \\
EcoR I-Forward & CTCGTAGACTGCGTACC \\
EcoR I-Reverse & AATTGGTACGCAGTCTAC \\
$M s e$ I-Forward & GACGATGAGTCCTGAG \\
$M s e$ I-Reverse & TACTCAGGACTCAT \\
Preselective primers & \\
EcoR I-A & GACTGCGTACCAATTCA \\
$M s e$ I-C & GACGATGAGTCCTGAGTAAC \\
Selective primers & \\
EcoR I-ACT $+M s e$ I-CAG & GAC TGC GTA CCA ATT CA \\
EcoR I-ACT $+M s e$ I-CAA & GAT GAG TCC TGA GTA AC \\
\hline
\end{tabular}
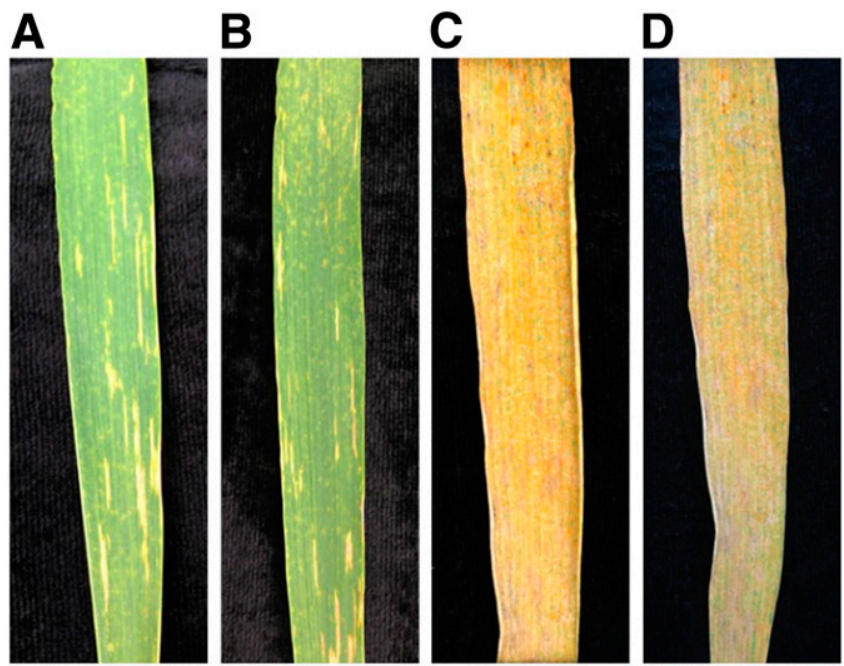

Fig. 1. Stripe rust responses of wheat lines A, CH4131, B, CH4132, C, CH4133, and D, $\mathrm{CH} 4134$ at adult plant stage. gluten gene subunit $5+10$, and cultivar Liangxing 99 (LX99) is a middle-gluten wheat variety. These materials were provided by the Wheat Research Institute, Shanxi Agricultural University, Linfen, Shanxi, China. To confirm the origin of the stripe rust resistance, a doubled haploid (DH) population (85 lines) was developed from a cross between the resistant line $\mathrm{CH} 4131$ and the susceptible line CH4133 using the wheat by maize pollination method (Yang et al. 2017) by operation in Yunnan Academy of Agricultural Sciences, Kunming, China.

Stripe rust testing. Z1141, CS, TC29, Shan 225, PH82-2-2, and $\mathrm{CH} 4131$ to $\mathrm{CH} 4134$ were planted in a randomized complete block nursery with three replicates in a field at Linfen, Shanxi province in 2011 to 2012,2012 to 2013,2013 to 2014, and 2014 to 2015. Twenty seeds of each line were planted evenly in single rows of $1-\mathrm{m}$ length with $33 \mathrm{~cm}$ between adjacent rows. MX169 was planted surrounding the nursery as an inoculum spreader to produce an epidemic environment. Eight races of Pst (CY29, CY31, CY32, CY33, CY34, Shuiyuan4, Shuiyuan5, and Shuiyuan7) were used in a mixture of equal quantity for inoculating plants at the wheat elongation stage. Stripe rust reaction were rated for infection type and recorded based on the 0 to 9 scale for signs and symptoms (Line and Qayoum 1992), with 1 being very resistant and 9 very susceptible. MX169 and Z1141 were used as the susceptible and resistant controls, respectively.

$\mathrm{F}_{1}$ plants and $\mathrm{DH}$ lines originating from the cross $\mathrm{CH} 4131 /$ CH4133 were assessed at the seedling stage using races CY32 and CY34 in the greenhouse at the College of Plant Protection, Northwest A\&F University, Yangling, Shaanxi province, in 2017 and 2018. Seedlings at the two-leaf stage were inoculated using urediniospores of each race mixed with talc (approximately 1:20). Plants were kept in the dark at $90 \%$ humidity and $10^{\circ} \mathrm{C}$ for $24 \mathrm{~h}$, and then, they were transferred into a greenhouse at $17 \pm 2^{\circ} \mathrm{C}$ with a 14-h photoperiod $(22,000 \mathrm{~lx})$ (Wu et al. 2018b). Stripe rust reactions were recorded 20 to 22 days after inoculation using the 0 to 9 scale as described above.

Cytogenetic analysis. Slide preparations were conducted according to Kato (1999) with some modifications (Huang et al. 2018). Total genomic DNA from Th. intermedium and Secale cereale was labeled with Texas red-5-dCTP by the nick translation method and used as probes. The detailed procedures of genomic in situ hybridization (GISH) were described by Liu et al. (2011a, b). Eight singlestrand oligonucleotides were used to detect the wheat chromosomes, including TAMRA (6-carboxytetramethylrhodamine)-modified AFA-3, AFA-4, pAs1-1, pAs1-3, pAs1-4, and pAs1-6 and FAM (6-carboxyfluorescein)-modified oligonucleotides pSc119.2-1 and $(\text { GAA })_{10}$. The general procedure of fluorescence in situ hybridization (FISH) was as described by Huang et al. (2018). Images were captured with an Olympus BX-60 fluorescence microscope (Olympus) equipped with a SPOT CCD (Olympus DP72) camera.

Amplified fragment-length polymorphism analysis. DNA was isolated from young leaves using an SDS (sodium dodecyl sulfate) protocol (Yang et al. 2006b). The amplified fragment-length polymorphism (AFLP) procedure was performed according to the protocol of Dhariwal et al. (2015). The restriction reaction contained $5 \mathrm{U}$ of EcoRI and $5 \mathrm{U}$ of $M s e \mathrm{I}$ in a final volume of $15 \mu \mathrm{l}$. The adaptors, preselective primers, and selective primers are listed in Table 1. The methods for cloning and sequencing relative polymorphic bands used were according to Sardesai et al. (2002).

PCR-based landmark unique gene PCR, intron targeting PCR, and $\omega$-sec PCR. PCR-based landmark unique gene (PLUG) and other EST (expressed sequence tags)-based molecular markers proved to be powerful tools in identifying the chromosome homologous group of alien species in wheat background (Gong et al. 2017; Liu et al. 2015, 2019). Therefore, in this study, a total of 526/841 PLUG/intron targeting (IT) primer pairs were synthesized according to Ishikawa et al. $(2007,2009)$ and Zhang et al. $(2017 a, b)$, respectively, to identify wheat-Th. intermedium cross progenies. Among these PLUG/IT primer pairs, 57/135, 67/175, 85/120, 71/89, 78/140, $59 / 71$, and $109 / 111$ pairs belonged to chromosome homologous groups 1 to 7, respectively. PLUG and IT primer pairs were 
synthesized by Chengdu Ruixin Biological Technology Co., Ltd. and Qingdao Qingke Biological Co., Ltd., and PCR protocol followed that according to Ishikawa et al. $(2007,2009)$ and Zhang et al. (2017 a, b). To obtain high levels of polymorphism, the PLUG PCR products were digested with the four-base cutter enzymes HaeIII and TaqI according to Ishikawa et al. (2007, 2009). Moreover, a pair of primers $\omega$-sec-P1 and $\omega$-sec-P2 for detecting rye $1 \mathrm{RS}$ chromosome in a wheat background was synthesized according to Chai et al. (2006). All PCR products were separated on $2 \%$ agarose gels.

Table 2. Stripe rust infection types produced in the adult plant-stage material tested in 2015

\begin{tabular}{lcccccccccc}
\hline & \multicolumn{10}{c}{ Infection type } \\
\cline { 2 - 10 } Cultivar & $\mathbf{0}$ & $\mathbf{1}$ & $\mathbf{2}$ & $\mathbf{3}$ & $\mathbf{4}$ & $\mathbf{5}$ & $\mathbf{6}$ & $\mathbf{7}$ & $\mathbf{8}$ & $\mathbf{9}$ \\
\hline Z1141 & 16 & 4 & - & - & - & - & - & - & - & - \\
Chinese Spring & - & - & - & - & - & - & - & - & - & 20 \\
Taichung29 & - & - & - & - & - & - & - & - & - & 20 \\
Shan 225 & - & - & - & - & - & - & - & - & - & 20 \\
CH4131 & - & - & 20 & - & - & - & - & - & - & - \\
CH4132 & - & - & 20 & - & - & - & - & - & - & - \\
CH4133 & - & - & - & - & - & - & - & - & - & 20 \\
CH4134 & - & - & - & - & - & - & - & - & - & 20 \\
PH82-2-2 & - & - & - & - & - & - & 20 & - & - & - \\
Mingxian169 & - & - & - & - & - & - & - & - & - & 20 \\
\hline
\end{tabular}

Agronomic traits assessment. The four translocation lines were assessed for agronomic performance in the field at Taiyuan and Linfen, Shanxi province, in 2015 and 2016. The experimental design consisted of three biological replicates arranged in a randomized block, with all plots and sites following the same standard cultivation practices and grown under irrigated conditions. The lines were sown in large-scale yield plots $(1.2 \times 6 \mathrm{~m})$, and they were sown by grain number for comparable plant densities per plot (345 seeds meter ${ }^{-2}$ ). Ten randomly selected plants in each plot were used to measure winter hardness, heading date, maturity date, spike length, spikelet number per spike, plant height, grain number per spike, effective tiller number, and 1,000-kernel weight (TKW). The harvested grain was used in quality analysis.

Quality analysis. Quality analysis was performed in the four translocation lines CH4131 to CH4134 and control LX99. The grains were milled using wheat grinding machine 3100 (Perten). Protein content was measured using a DA7200 diode array near-infrared spectrometer (Perten). Wet gluten content was analyzed using a Glutomatic 2200 (Perten) according to the American Association of Cereal Chemists International (2000). A farinograph (Brabender) was used to examine the dough stability time and formation time, and an extensograph (Brabender) was used to examine the maximum resistance to drag and stretch area. The seed high-molecular weight glutenin subunits (HMW-GSs) were extracted and examined by sodium dodecyl sulfate polyacrylamide gel electrophoresis according to the method described by Zhao et al. (2018).

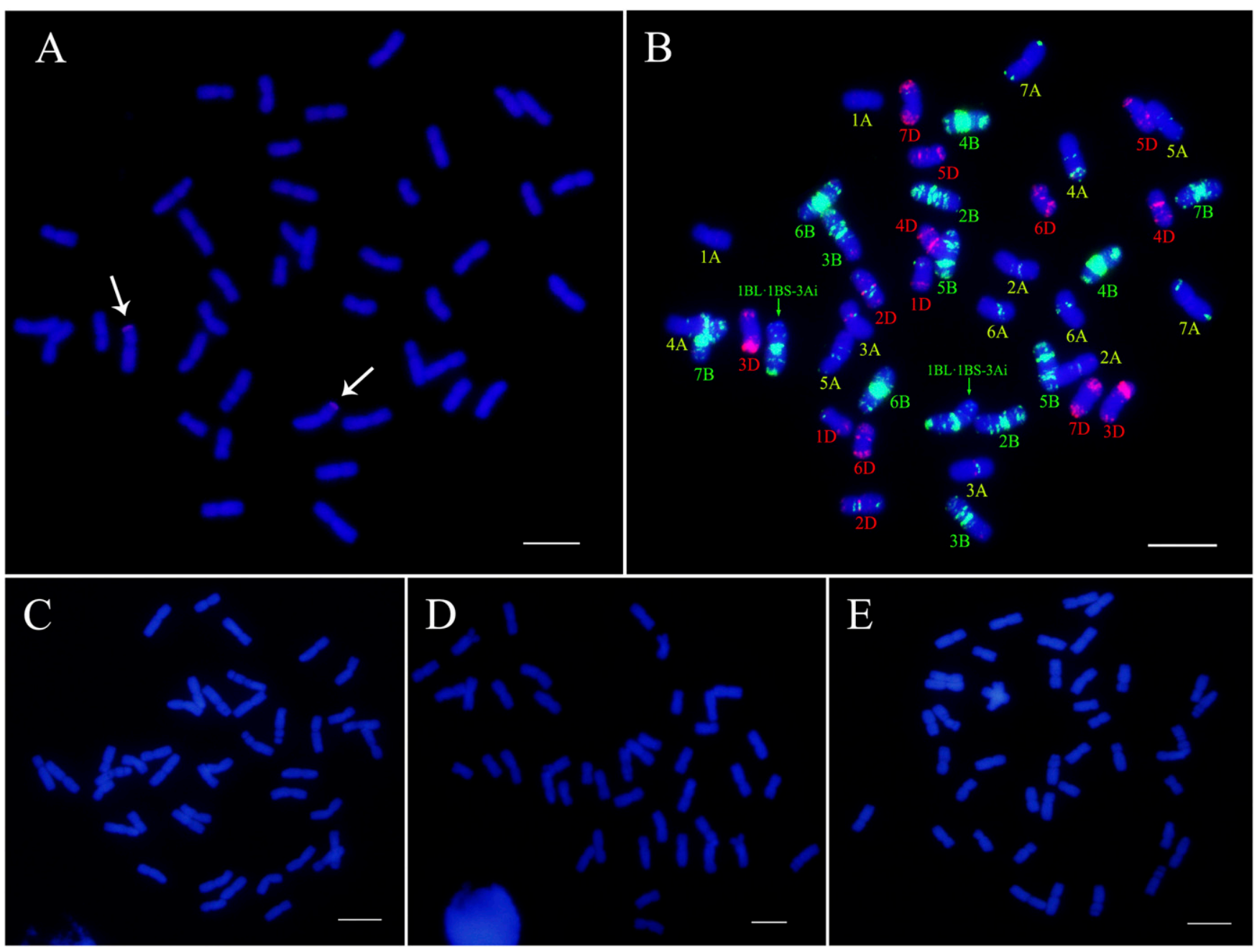

Fig. 2. Genomic in situ hybridization (GISH) and fluorescence in situ hybridization (FISH) analysis on metaphase chromosomes of $\mathbf{A}$ to C, CH4131, D, cultivar Shan 225, and E, PH82-2-2. A, GISH using genomic DNA of Thinopyrum intermedium as probe and genomic DNA of Chinese Spring as block. B, FISH using oligonucleotide multiplex probe. Green signals show pSc119.2-1 and (GAA) 10 modified with 6-carboxyfluorescein, and red signals show oligonucleotides pAs1-1, pAs1-3, pAs1-4, pAs1-6, AFA-3, and AFA-4 modified with 6-carboxytetramethylrhodamine. C, GISH using genomic DNA of rye as probe. D, GISH of Shan 225 using genomic DNA of Th. intermedium as probe. E, GISH of PH82-2-2 using genomic DNA of Th. intermedium as probe. Scale bar: $10 \mu \mathrm{m}$. 


\section{Results}

Reaction to stripe rust inoculation in the four translocation lines. Z1141 showed an immune reaction (IT 0) on 16 plants and high resistance (IT 1) on 4 plants. $\mathrm{CH} 4131$ and $\mathrm{CH} 4132$ showed high resistance with IT 2, whereas CH4133 and CH4134 showed high susceptibility with IT 9 (Fig. 1). The four wheat lines used to develop CH4131 to CH4132 were either moderately susceptible (IT 6) for PH82-2-2 or highly susceptible (IT 9) for CS, TC29, and Shan 225 (Table 2). These results showed that $\mathrm{CH} 4131$ and $\mathrm{CH} 4132$ had stripe rust resistance and indicated that the resistance most likely was from the Th. intermedium line Z1141.

The chromosome composition of wheat-Th. intermedium introgressions. Chromosome counting indicated that the total number of chromosomes of $\mathrm{CH} 4131$ to $\mathrm{CH} 4134$ was 42 . Using genomic DNA of Th. intermedium as the probe and genomic DNA of CS as the block, GISH was performed on the metaphase chromosomes of $\mathrm{CH} 4131$ to $\mathrm{CH} 4134$. As a result, a pair of small chromosome segment translocations was detected in both $\mathrm{CH} 4131$ (Fig. 2A) and CH4132 with the same signals, whereas no GISH signal was detected in susceptible lines $\mathrm{CH} 4133$ and $\mathrm{CH} 4134$.

To identify the translocated wheat chromosomes, after washing off the GISH signals, FISH was subsequently performed using the oligonucleotide multiplex probe on the metaphase chromosomes of the same cell as the one used for GISH. As a result, the translocated wheat chromosomes in $\mathrm{CH} 4131$ (Fig. 2B) and CH4132 (FISH signals were the same as in CH4131) were 1B. GISH using the DNA from $S$. cereale (Fig. 2C) showed no signals; meanwhile, rye 1RSspecific marker $\omega$-sec-P1/ $\omega$-sec-P2 did not amplify the 1,100 -base pair band in $\mathrm{CH} 4131$ to $\mathrm{CH} 4134$ (Supplementary Fig. S1), indicating that they were not $1 \mathrm{BL} / 1 \mathrm{RS}$ translocation lines.

Among the parents of $\mathrm{CH} 4131$ to $\mathrm{CH} 4134, \mathrm{CS}$ and TC29 are wheat cultivars, whereas PH82-2-2 and Shan 225 are wheat-Thinopyrum ponticum derivatives. To clearly identify the origin of translocated alien chromosome segments, GISH was also performed on the metaphase chromosomes of PH82-2-2 and Shan 225; however, no GISH signals were detected (Fig. 2D and E), indicating that the translocated alien chromosome segments are from Z1141.

Markers for precisely identifying wheat-Th. intermedium introgressions. In wheat-Th. intermedium introgressions lines CH4131 and CH4132, chromosomes 1B of wheat were involved in the chromosome translocation (Fig. 2A and B). However, the homologous group of Th. intermedium chromosome in the translocation remains unknown. To elucidate this, AFLP was conducted on the material tested to gain specific sequences of Th. intermedium in the introgression lines. As a result, six polymorphic bands were obtained (Supplementary Fig. S2). All of these six polymorphic bands were cloned and sequenced. The sequence lengths of 258, 201, 242, 224, and 187 base pairs were obtained from primer combinations A- to E (Table 3 and Supplementary Text S1). BlastN searches revealed that three sequences (A, D, and E) were highly homologous to sequence fragments of $T$. aestivum chromosome $3 \mathrm{~B}$, whereas sequence $\mathrm{C}$ was highly homologous to Aegilops speltoides mitochondrial DNA, and no sequence was found homologous to sequence B. Within these five cloned sequences, three sequences belonged to chromosome homologous group 3 .
To further identify the homologous determination of the translocation segments of Th. intermedium, PLUG and IT primer pairs that belonged to the chromosome homologous groups 1 to 7 were used to amplify the genomic DNA of Th. bessarabicum, Th. elongatum, P. strigosa, Th. intermedium, CS, TC29, PH82-2-2, Shan 225, and $\mathrm{CH} 4131$ to $\mathrm{CH} 4134$. As a result, no polymorphic marker was generated by PLUG primer pairs. However, four IT primer pairs (CINAU1231, CINAU1233, CINAU1204, and CINAU1171) could generate additional polymorphism DNA bands in lengths of 480 , 520, 100, and 550 base pairs in Th. elongatum, Th. intermedium, CH4131, and CH4132 (Fig. 3A to C), respectively. All of these four markers were derived from the chromosome homologous group 3 of Dasypyrum villosum. Therefore, the Th. intermedium chromosome segments in $\mathrm{CH} 4131$ and $\mathrm{CH} 4132$ belong to homologous group 3, which was consistent with the AFLP marker result.

Based on the cloned AFLP sequence of B, a pair of sequencecharacterized amplified region (SCAR) primers D05-A4-1F (5'CCGATGGAGGACTTTGTAG-3') and D05-A4-1R (5'GCTTACTTGTTGGACCTTG-3') was designed to develop SCAR markers. PCR using this pair of primers was performed on the material tested; the result showed that a polymorphic band (D05-A4-1), 163 base pairs in length, was generated in Z1141, CH4131, and $\mathrm{CH} 4132$, but no amplicon was detected in the other material tested (Fig. 3D), indicating that D05-A4-1 together with the four IT polymorphic bands could be used as molecular marker for tracing the Th. intermedium chromatin in wheat breeding programs.

PCR using the SCAR and IT primer pairs on Th. bessarabicum, Th. elongatum, P. strigose, Th. intermedium, CS, TC29, PH82-2-2, Shan 225, and $\mathrm{CH} 4131$ to $\mathrm{CH} 4134$ showed that only Th. elongatum, Th. intermedium, $\mathrm{CH} 4131$, and $\mathrm{CH} 4132$ had the targeted segments (Fig. 3), indicating that the chromosome segments of Th. intermedium in $\mathrm{CH} 4131$ and $\mathrm{CH} 4132$ belonged to chromosome homologous 3 . Because the Th. elongatum used in this experiment was only from one population, the chromosome configurations of the two translocation lines were named as T3Ai-1BS.1BL instead of T3E $\mathrm{E}^{\mathrm{e}}-1 \mathrm{BS} .1 \mathrm{BL}$.

Verification of the source of stripe rust resistance using the SCAR marker. Stripe rust responses were evaluated on seedlings of

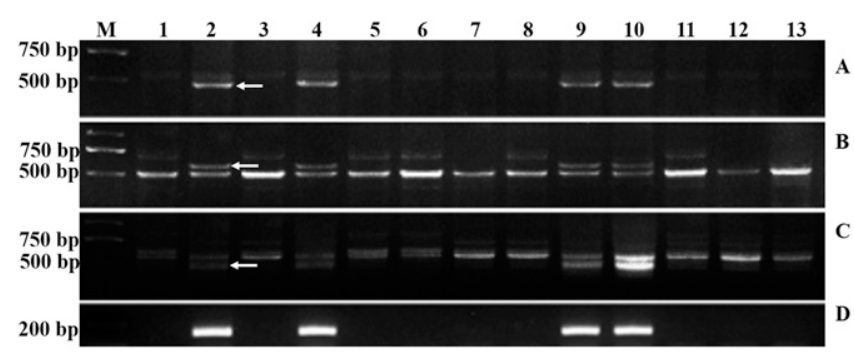

Fig. 3. PCR patterns of infection-type markers A, CINAU1231, B, CINAU1171, and C, CINAU1233 and D, sequence-characterized amplified region marker D05-A4-1F/1R. Arrows show the polymorphism DNA bands. M, marker; 1, Thinopyrum bessarabicum; 2, Thinopyrum elongatum; 3, Pseudoroegneria strigose; 4, Thinopyrum intermedium; 5, Chinese Spring; 6, Taichung29; 7, PH82-2-2; 8 , cultivar Shan 225; 9, CH4131; 10, CH4132; 11, CH4133; 12, CH4134; 13, ddH 20 .

Table 3. Sequencing results of amplified fragment-length polymorphism special bands

\begin{tabular}{|c|c|c|c|c|}
\hline No. & Primer combination name & Length (base pairs) & Homologous sequence & E value \\
\hline A & $E c o R I-A C T+M s e I-C A G-258$ & 258 & $\begin{array}{l}\text { Triticum aestivum chromosome 3B } \\
\text { (FN564426.1) }\end{array}$ & $5 e-21$ \\
\hline B & $E c o R I-A C T+M s e I-C A G-201$ & 201 & None & - \\
\hline $\mathrm{C}$ & $E c o R I-A C T+M s e I-C A A-242$ & 242 & $\begin{array}{l}\text { Aegilops speltoides mitochondrial DNA } \\
\text { (AP013107.1) }\end{array}$ & $4 \mathrm{e}-110$ \\
\hline $\mathrm{D}$ & $E c o R \mathrm{I}-\mathrm{ACT}+M s e \mathrm{I}-\mathrm{CAA}-224$ & 224 & $\begin{array}{l}\text { Triticum aestivum chromosome 3B } \\
\text { (FN645450.1) }\end{array}$ & $9 e-61$ \\
\hline E & $E c o R \mathrm{I}-\mathrm{ACT}+M s e \mathrm{I}-\mathrm{CAA}-187$ & 187 & $\begin{array}{l}\text { Triticum aestivum chromosome 3B } \\
\text { (FN564428.1) }\end{array}$ & $2 \mathrm{e}-54$ \\
\hline $\mathrm{F}$ & EcoRI-ACT + MseI-CAA-NONE & None & - & - \\
\hline
\end{tabular}


$\mathrm{F}_{1}$ and the $\mathrm{DH}$ population originating from the cross $\mathrm{CH} 4131 / \mathrm{CH} 4133$. CH4131 showed broad spectrum resistance to eight stripe rust races, and therefore, a mixture of prevalent races (CY32 and CY34) was utilized to inoculate the $\mathrm{F}_{1}$ plants and the $\mathrm{DH}$ lines. All $\mathrm{F}_{1}$ plants and 44 DH lines were highly resistant to CY32 and CY34 (IT 0), whereas $41 \mathrm{DH}$ lines were highly susceptible (IT 9) (Fig. 4). The seedling assay of the $\mathrm{DH}$ population segregated in a 1:1 ratio (Supplementary Table $\mathrm{S} 1$ ), and $\mathrm{F}_{1}$ plants were resistant, indicating that a single dominant gene was involved in the $\mathrm{CH} 4131$ resistance.

\section{CY32}

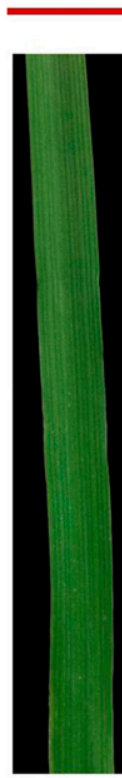

A

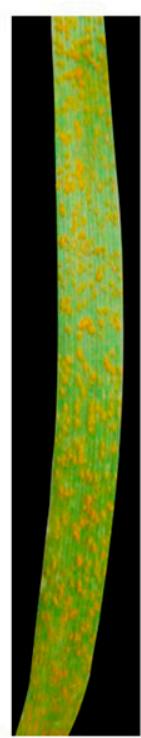

B

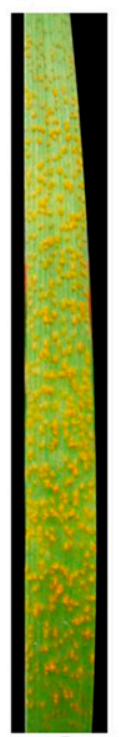

C

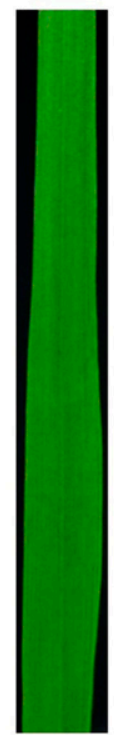

D

\section{CY34}

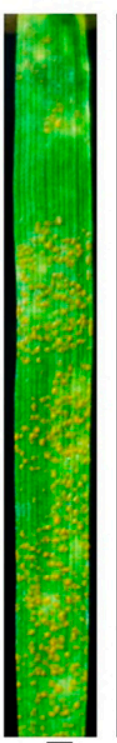

E

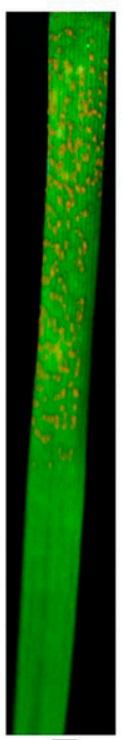

$\mathbf{F}$
Fig. 4. Stripe rust responses of doubled haploid lines inoculated with races $\mathrm{CY} 32$ and CY34 of Puccinia striiformis f. sp. tritici. Doubled haploid lines that are highly resistant to $A, C Y 32$ and $\mathbf{D}, \mathbf{C Y} 34$. Doubled haploid lines that are highly susceptible to $B, C Y 32$ and $\mathbf{E}, \mathrm{CY} 34$. Cultivar (Mingxian169) is highly susceptible to C, CY32 and F, CY34.
Genotyping the DH population with the SCAR marker showed that stripe rust resistance was closely linked with the SCAR marker, because all resistant lines had the SCAR amplification, whereas the susceptible lines had no amplification (Supplementary Fig. S3), confirming that the stripe rust resistance was from the translocated $T h$. intermedium 3Ai.

Agronomic performance of the translocation lines. Both $\mathrm{CH} 4131$ and $\mathrm{CH} 4132$ possess the stripe rust resistance gene, suggesting that they were an excellent gene source for wheat improvement. However, it remains unknown whether they have any genetic drag for undesirable agronomic traits. To evaluate these lines, agronomic traits investigation and quality analysis were performed. Based on the field data, $\mathrm{CH} 4131$ to $\mathrm{CH} 4134$ are facultative winter wheat. Leaves are dark green. There were no significant differences among CH4131 to $\mathrm{CH} 4134$ in spike length, spikelet number, and effective tiller number, but there were differences in the TKW value, plant height, and maturity (Fig. 5A and Supplementary Table S2). The translocation lines were later and taller, and they had smaller TKW than the nontranslocation lines (Fig. 5B).

Quality analysis. Quality analysis suggested that there were no significant differences in protein content, sedimentation volume, wet gluten content, dough stability time, formation time, and maximum resistance to drag and stretch area among $\mathrm{CH} 4131$ to $\mathrm{CH} 4134$. The quality indexes of the four lines were higher than middle-gluten wheat variety LX99 (Table 4). HMW-GS analysis showed that the components of subunits $G l u-A 1, G l u-B 1$, and Glu$D 1$ of these four lines were null: $14+15$ and $2+12$ (Fig. 6 ). Therefore, $\mathrm{CH} 4131$ to $\mathrm{CH} 4134$ are well suitable for making noodles and steamed bread.

\section{Discussion}

Thinopyrum species are important gene sources for wheat improvement. Th. intermedium can be crossed with wheat easily, and the derived wheat-Th. intermedium introgression lines have played an important role in both wheat chromosome engineering research and wheat breeding programs. So far, different research groups have developed disease-resistant wheat-Thionpyrum amphiploids or partial amphiploids, such as Zhong1 to Zhong5 (Han et al. 2004; Tian et al. 2000), Otrastsjuskaya (Fedak et al. 2000), TE-3 (Yang et al. 2006a), TAI8335 (Chang et al. 2010), TE253 (Bao et al. 2009), and
A

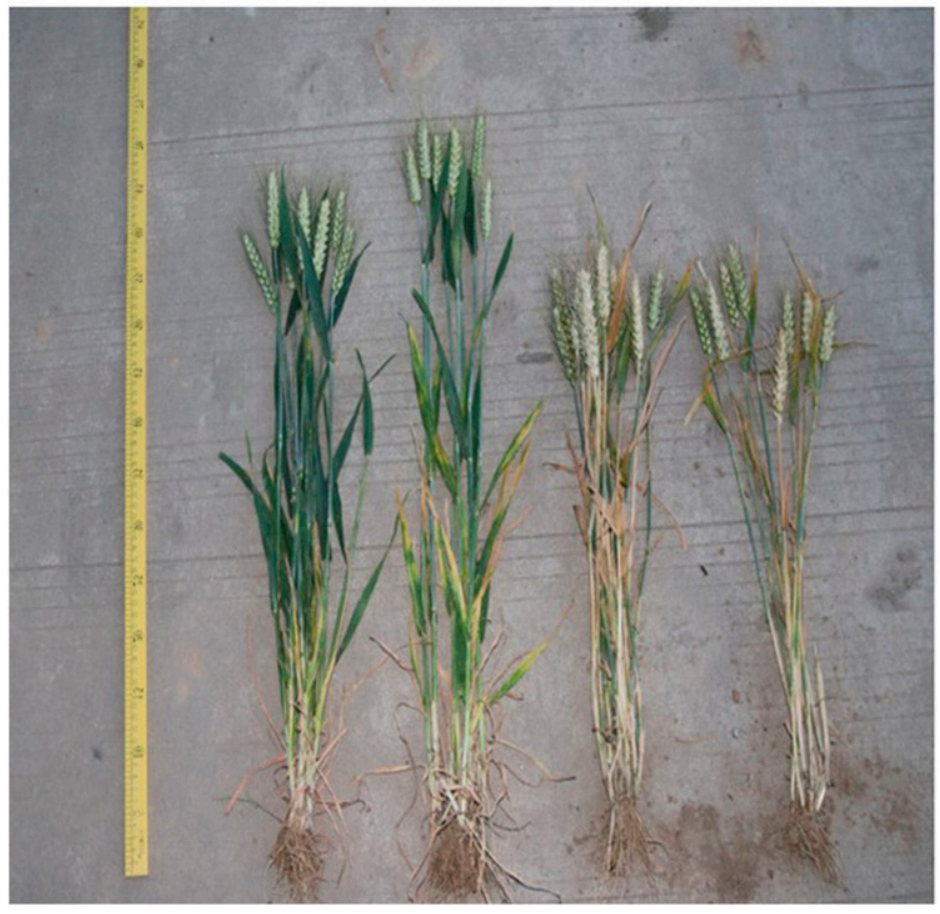

B

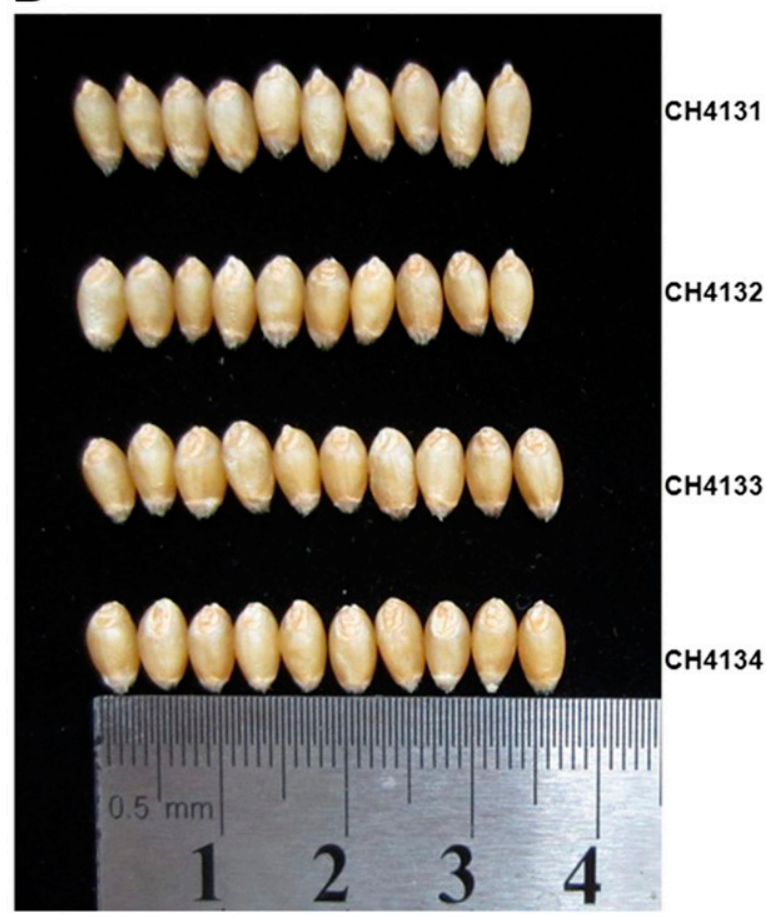

Fig. 5. Morphologies of A, plants and B, grain width of $\mathrm{CH} 4131$ to $\mathrm{CH} 4134$. 
Table 4. Quality traits of the material tested

\begin{tabular}{|c|c|c|c|c|c|c|c|}
\hline Cultivar & $\begin{array}{c}\text { Protein content } \\
(\%)\end{array}$ & $\begin{array}{l}\text { Sedimentation } \\
\text { volume }(\mathbf{m l})\end{array}$ & $\begin{array}{l}\text { Wet gluten } \\
\text { content }(\%)\end{array}$ & $\begin{array}{l}\text { Dough stability time } \\
\text { (min) }\end{array}$ & $\begin{array}{l}\text { Formation time } \\
\text { (min) }\end{array}$ & $\begin{array}{c}\text { Maximum } \\
\text { resistance } \\
\text { to drag }(\mathbf{E U})\end{array}$ & $\begin{array}{c}\text { Stretch area } \\
\left(\mathrm{cm}^{2}\right)\end{array}$ \\
\hline CH4131 & $14.36 \pm 1.42 \mathrm{a}^{\mathrm{z}}$ & $29.51 \pm 1.34 \mathrm{ab}$ & $32.88 \pm 2.76 a$ & $6.7 \pm 0.45 \mathrm{a}$ & $3.7 \pm 0.12 \mathrm{a}$ & $212 \pm 15.44 \mathrm{a}$ & $47 \pm 3.93 \mathrm{a}$ \\
\hline CH4132 & $14.87 \pm 1.58 \mathrm{a}$ & $32.84 \pm 3.21 \mathrm{a}$ & $33.01 \pm 3.23 \mathrm{a}$ & $7.9 \pm 0.49 \mathrm{a}$ & $3.6 \pm 0.33 \mathrm{a}$ & $220 \pm 14.23 \mathrm{a}$ & $48 \pm 2.65 \mathrm{a}$ \\
\hline CH4133 & $14.49 \pm 1.16 \mathrm{a}$ & $31.67 \pm 3.09 \mathrm{a}$ & $32.86 \pm 1.98 \mathrm{a}$ & $7.7 \pm 0.56 \mathrm{a}$ & $3.6 \pm 0.24 \mathrm{a}$ & $214 \pm 18.87 \mathrm{a}$ & $47 \pm 2.15 \mathrm{a}$ \\
\hline CH4134 & $14.71 \pm 1.25 \mathrm{a}$ & $32.05 \pm 2.78 \mathrm{a}$ & $33.44 \pm 3.02 \mathrm{a}$ & $7.3 \pm 0.77 \mathrm{a}$ & $3.5 \pm 0.28 \mathrm{a}$ & $209 \pm 17.34 \mathrm{ab}$ & $46 \pm 3.72 \mathrm{a}$ \\
\hline Liangxing 99 & $13.32 \pm 0.84 b$ & $26.81 \pm 1.26 \mathrm{~b}$ & $30.61 \pm 1.82 b$ & $2.1 \pm 0.44 b$ & $2.7 \pm 0.23 b$ & $193 \pm 15.27 \mathrm{~b}$ & $42 \pm 3.72 b$ \\
\hline
\end{tabular}

${ }^{\mathrm{z}}$ Different letters are used to indicate means that differ significantly $(P<0.05$, least significant difference test).

CH13-21 (Zhan et al. 2015). Using these amphiploids/partial amphipliods as a bridge, Wan et al. (1999) created seven wheat-Th. intermedium addition lines and concluded that at least two pairs of St chromosomes of Th. intermedium possess stripe rust resistance genes. Later, Li et al. (2006) transferred an unnamed stripe rust resistance gene from chromosome St of Th. intermedium ssp. trichophorum to common wheat. Subsequently, Liu et al. (2007) reported that they transferred stripe rust resistance gene $\mathrm{YrSt}$ from chromosome St of Th. ponticum to a cultivated wheat variety. Hao et al. (2012) identified a stripe rust-resistant wheat-Th. ponticum $4 \mathrm{D} / 4 \mathrm{St}$ translocation line and speculated that the resistance was from $4 \mathrm{St}$ of $\mathrm{Th}$. ponticum. Luo et al. (2009) transferred resistance gene YrYU25 from Th. intermedium to hexaploid wheat. Hu et al. (2011) transferred the resistance from chromosome $6 \mathrm{~J}^{\mathrm{s}}$ of Th. ponticum to wheat and created a $6 \mathrm{~J}^{\mathrm{s}}(6 \mathrm{~B})$ substitution line. Liu et al. (2013a, b) mapped a putative $T h$. intermedium-derived stripe rust resistance gene $Y r 50$ on wheat chromosome arm 4BL. Hou et al. (2016) mapped Yr69 on 2AS of a stripe rust-resistant wheat-Th. ponticum cryptic introgression. However, none of the alien resistance genes mentioned above were from chromosome homologous 3. Ma et al. (1999) mapped a primary designated gene $\operatorname{YrE}$ on chromosome $3 \mathrm{E}^{\mathrm{e}}$ of Th. elongatum. Nevertheless, $\operatorname{YrE}$ does not exist in the form of a wheat-Th. elongatum chromosome translocation; therefore, it is not available for breeding. In this study, we identified two stripe rust-resistant wheat-Th. intermedium T3Ai1BS.1BL translocations $\mathrm{CH} 4131$ and $\mathrm{CH} 4132$. Both translocation lines are an excellent gene source for wheat breeding. The stripe rust resistance gene described in this study is different from $\operatorname{Yr} 50$ (4BL) and Yr69 (2AS) and might be the same gene or an allele of the temporarily named $\mathrm{YrE}$. Therefore, this gene is clearly different from permanently named $\mathrm{Yr}$ genes and is designated as $\mathrm{YrCH}-\mathrm{IBS}$.

Germplasm innovation based on chromosome engineering has always played an important role in discovering exogenous excellent genes. It can be applied to rapid, accurate, and consistent improvement in breeding high-yielding and high-quality wheat cultivars that have resistance to multiple diseases. There are several hundred disease resistance genes that have been designated. Some of these genes that have come from wild relatives of wheat were highly valued by wheat breeders and pathologists (Liu et al. 2012). However, not all of the resistance genes from wild wheat species could be used widely in breeding programs because of the linkage of genes for undesirable traits. In this study, we comprehensively evaluated the agronomic traits and quality of the stripe rust-resistant wheat-Th. intermedium lines with the T3Ai-1BS.1BL translocation. The translocated

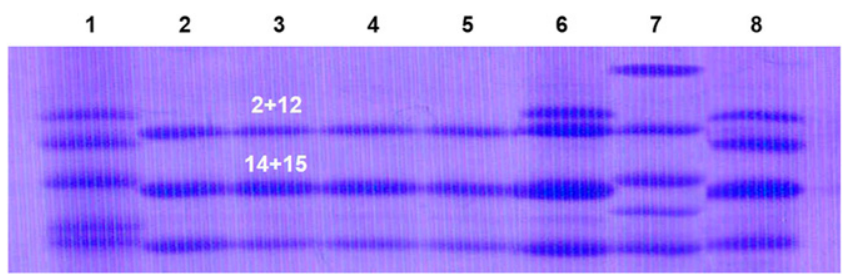

Fig. 6. High-molecular weight glutenin subunit analysis of the material tested by sodium dodecyl sulfate polyacrylamide gel electrophoresis. 1, Zhongyou 9507; 2, $\mathrm{CH} 4131 ; 3$, CH4132; 4, CH4133; 5, CH4134; 6, PH82-2-2; 7, Taichung29; 8, cultivar Shan 225 chromosome fragments have no obvious linkage drag to agronomic and grain quality performance. Therefore, they could be widely used in wheat improvement. The SCAR and IT markers, which were cosegregating with $\mathrm{YrCH}-1 \mathrm{BS}$, may be useful in stripe rust improvement.

\section{Acknowledgments}

We thank Prof. Z. J. Qi, Cytogenetics Institute, Nanjing Agricultural University, for critical review of this manuscript and Mr. M. L. Ding, Food Crops Research Institute, Yunnan Academy of Agricultural Sciences, for providing help in developing doubled haploid populations. We also acknowledge help from Dr. Q. L. Wang, Northwest A\&F University, with resistance testing and Dr. Y. G. Bao, College of Agronomy, Shandong Agricultural University, for providing help in the fluorescence in situ hybridization and genomic in situ hybridization procedures.

\section{Literature Cited}

American Association of Cereal Chemists International. 2000. AACC Approved Methods, 10th Ed. Cereals \& Grains Association, St. Paul, MN

Bai, B., Du, J. Y., Lu, Q. L., He, C. Y., Zhang, L. J., Zhou, G., Xia, X. C., He, Z. H., and Wang, C. S. 2014. Effective resistance to wheat stripe rust in a region with high disease pressure. Plant Dis. 98:891-897.

Bao, Y., Li, X., Liu, S., Cui, F., and Wang, H. 2009. Molecular cytogenetic characterization of a new wheat-Thinopyrum intermedium partial amphiploid resistant to powdery mildew and stripe rust. Cytogenet. Genome Res. 126:390-395.

Brown, J. K. M. 2015. Durable resistance of crops to disease: A Darwinian perspective. Annu. Rev. Phytopathol. 53:513-539.

Cenci, A., D’Ovidio, R., Tanzarella, O. A., Ceoloni, C., and Porceddu, E. 1999. Identification of molecular markers linked to Pm13, an Aegilops longissima gene conferring resistance to powdery mildew in wheat. Theor. Appl. Genet. 98:448-454

Chai, J. F., Zhou, R. H., Jia, J. Z., and Liu, X. 2006. Development and application of a new codominant PCR marker for detecting $1 \mathrm{BL} \cdot 1 \mathrm{RS}$ wheat-rye chromosome translocations. Plant Breed. 125:302-304.

Chang, Z. J., Zhang, X. J., Yang, Z. J., Zhan, H. X., Li, X., Liu, C., and Zhang, C. Z. 2010. Characterization of a partial wheat-Thinopyrum intermedium amphiploid and its reaction to fungal diseases of wheat. Hereditas 147:304-312.

Chen, X. M. 2005. Epidemiology and control of stripe rust [Puccinia striiformis $\mathrm{f}$. sp. tritici] on wheat. Can. J. Plant Pathol. 27:314-337.

Chen, X. M., and Zhao, J. 2007. Identification of molecular markers for $\operatorname{Yr} 8$ and a gene for high-temperature, adult-plant resistance against stripe rust in the AVS/ 6*Yr8 wheat line. Phytopathology 97:S21.

Dhariwal, R., Gahlaut, V., Govindraj, B. R., Singh, D., Mathur, S., Vyas, S., Bandopadhyay, R., Khurana, J. P., Tyagi, A. K., Prabhu, K. V., Mukhopadhyay, K., Balyan, H. S., and Gupta, P. K. 2015. Stage-specific reprogramming of gene expression characterizes Lr48-mediated adult plant leaf rust resistance in wheat. Funct. Integr. Genomics 15:233-245.

Fedak, G., Chen, Q., Conner, R. L., Laroche, A., Petroski, R., and Armstrong, K. W. 2000. Characterization of wheat-Thinopyrum partial amphiploids by meiotic analysis and genomic in situ hybridization. Genome 43:712-719.

Friebe, B., Jiang, J., Knott, D. R., and Gill, B. S. 1994. Compensation indices of radiation-induced wheat-Agropyron elongatum translocations conferring resistance to leaf rust and stem rust. Crop Sci. 34:400-404.

Gong, W. P., Han, R., Li, H. S., Song, J. M., Yan, H. F., Li, G. Y., Liu, A. F., Cao, X. Y., Guo, J., Zhai, S. N., Cheng, D. G., Zhao, Z. D., Liu, C., and Liu, J. J. 2017. Agronomic traits and molecular marker identification of wheatAegilops caudata addition lines. Front. Plant Sci. 8:1743.

Han, F. P., Liu, B., Fedak, G., and Liu, Z. H. 2004. Genomic constitution and variation in five partial amphiploids of wheat-Thinopyrum intermedium as revealed by GISH, multicolor GISH and seed storage protein analysis. Theor. Appl. Genet. 109:1070-1076.

Hao, W. W., Tang, C. G., Li, B. C., Hao, C. Y., and Zhang, X. Y. 2012. Analysis of wheat-Thinopyrum ponticum translocation lines with broad spectrum resistance to stripe rusts. Sci. Agric. Sin. 45:3240-3248.

Hou, L. Y., Jia, J. Q., Zhang, X. J., Li, X., Yang, Z. J., Ma, J., Guo, H. J., Zhan, H. X., Qiao, L. Y., and Chang, Z. J. 2016. Molecular mapping of the stripe rust resistance gene Yr69 on wheat chromosome 2AS. Plant Dis. 100:1717-1724.

Hovmøller, M. S., Walter, S., Bayles, R. A., Hubbard, A., Flath, K., Sommerfeldt, N., Leconte, M., Czembor, P., Rodriguez-Algaba, J., Thach, T., Hansen, J. G., 
Lassen, P., Justesen, A. F., Ali, S., and Vallavieille-Pope, C. 2016. Replacement of the European wheat yellow rust population by new races from the centre of diversity in the near-Himalayan region. Plant Pathol. 65:402-411.

Hovmøller, M. S., Yahyaoui, A. H., Milus, E. A., and Justesen, A. F. 2008. Rapid global spread of two aggressive strains of a wheat rust fungus. Mol. Ecol. 17:3818-3826.

Hu, L. J., Li, G. R., Zeng, Z. X., Chang, Z. J., Liu, C., and Yang, Z. J. 2011. Molecular characterization of a wheat - Thinopyrum ponticum partial amphiploid and its derived substitution line for resistance to stripe rust. J. Appl. Genet. 52:279-285.

Huang, X. Q., and Röder, M. S. 2004. Molecular mapping of powdery mildew resistance genes in wheat: A review. Euphytica 137:203-223.

Huang, X. Y., Zhu, M. Q., Zhuang, L. F., Zhang, S. Y., Wang, J. J., Chen, X. J., Wang, D. R., Chen, J. Y., Bao, Y. G., Guo, J., Zhang, J. L., Feng, Y. G., Chu, C. G., Du, P., Qi, Z. J., Wang, H. G., and Chen, P. D. 2018. Structural chromosome rearrangements and polymorphisms identifed in Chinese wheat cultivars by highresolution multiplex oligonucleotide FISH. Theor. Appl. Genet. 131:1967-1986.

Hurni, S., Brunner, S., Buchmann, G., Herren, G., Jordan, T., Krukowski, P., Wicker, T., Yahiaoui, N., and Keller, B. 2013. Rye $P m 8$ and wheat $P m 3$ are orthologous genes and show evolutionary conservation of resistance function against powdery mildew. Plant J. 76:957-969.

Ishikawa, G., Nakamura, T., Ashida, T., Nasuda, S., Endo, T. R., Wu, J. Z., and Matsumoto, T. 2009. Localization of anchor loci representing five hundred annotated rice genes to wheat chromosomes using PLUG markers. Theor. Appl. Genet. 118:499-514.

Ishikawa, G., Yonemaru, J., Saito, M., and Nakamura, T. 2007. PCR-based landmark unique gene (PLUG) markers effectively assign homoeologous wheat genes to A, B and D genomes. BMC Genomics 8:135.

Kato, A. 1999. Air drying method using nitrous oxide for chromosome counting in maize. Biotech. Histochem. 74:160-166.

Lang, T., La, M. S., Li, B., Yu, Z. H., Chen, Q. H., Li, J. B., Yang, E. N., Li, G. R., and Yang, Z. J. 2018. Precise identification of wheat-Thinopyrum intermedium translocation chromosomes carrying resistance to wheat stripe rust in line Z4 and its derived progenies. Genome 61:177-185.

Li, G. R., Wang, H. J., Lang, T., Li, J. B., La, S. X., Yang, E. N., and Yang, Z. J. 2016. New molecular markers and cytogenetic probes enable chromosome identification of wheat-Thinopyrum intermedium introgression lines for improving protein and gluten contents. Planta 244:865-876.

Li, G. R., Yang, Z. J., and Chang, Z. J. 2006. Molecular cytogenetics identification of a wheat-Thinopyrum intermedium ssp. trichophorum addition line Y176-3. J. Triticeae Crops 26:20-23.

Line, R. F., and Qayoum, A. 1992. Virulence, aggressiveness, evolution and distribution of races of Puccinia striiformis (the cause of stripe rust of wheat) in North America, 1968-87. Technical Bulletin no. 1788, U.S. Department of Agriculture, Pullman, WA

Liu, A. F., Wang, H. G., Hao, Y. F., Duan, Y. C., Wang, Y. H., Wu, X. R., Li, Y., Zhu, Y. L., and Gao, J. R. 2007. Identification of Tritielytrigia alien disomic addition line Shannong 87074-519 with yellow rust resistance. J. Mol. Cell Biol. 40:217-223.

Liu, C., Gong, W. P., Han, R., Guo, J., Li, G. R., Li, H. S., Song, J. M., Liu, A. F., Cao, X. Y., Zhai, S. N., Cheng, D. G., Li, G. Y., Zhao, Z. D., Yang, Z. J., Liu, J. J., and Reader, S. M. 2019. Characterization, identification and evaluation of a set of wheat-Aegilops comosa chromosome lines. Sci. Rep. 9:4773.

Liu, C., Li, G., Yan, H., Zhou, J., Hu, L., Lei, M., Ran, L., and Yang, Z. 2011 a. Molecular and cytogenetic identification of new wheat - Dasypyrum breviaristatum additions conferring resistance to stem rust and powdery mildew. Breed. Sci. 61:366-372.

Liu, C., Li, G. R., Gong, W. P., Li, G. Y., Han, R., Li, H. S., Song, J. M., Liu, A. F., Cao, X. Y., Chu, X. S., Yang, Z. J., Huang, C. Y., Zhao, Z. D., and Liu, J. J. 2015. Molecular and cytogenetic characterization of powdery mildew resistant wheat-Aegilops mutica partial amphiploid and addition line. Cytogenet Genome Res. 147:186-194.

Liu, J., Chang, Z. J., Zhang, X. J., Yang, Z. J., Li, X., Jia, J. P., Zhan, H. X., Guo, H. J., and Wang, J. M. 2013a. Putative Thinopyrum intermedium-derived stripe rust resistance gene $\operatorname{Yr} 50$ maps on wheat chromosome arm 4BL. Theor. Appl. Genet. 126:265-274

Liu, W., Danilova, T. V., Rouse, M. N., Bowden, R. L., Friebe, B., Gill, B. S., and Pumphrey, M. O. 2013b. Development and characterization of a compensating wheat-Thinopyrum intermedium Robertsonian translocation with $\mathrm{Sr} 44$ resistance to stem rust (Ug99). Theor. Appl. Genet. 126:1167-1177.

Liu, W., Seifers, D. L., Qi, L. L., Friebe, B., and Gill, B. S. 2011 b. A compensating wheat-Thinopyrum intermedium Robertsonian translocation conferring resistance to wheat streak mosaic virus and Triticum mosaic virus. Crop Sci. 51:2382-2390.

Liu, Y. N., He, Z. H., Appels, R., and Xia, X. C. 2012. Functional markers in wheat: Current status and future prospects. Theor. Appl. Genet. 125:1-10.

Liu, Z. Y., Sun, Q. X., Li, H. J., Ni, Z. F., Yang, Z. M., Tang, B. R., Yang, A. D., and Jia, X. 1999. Molecular identification and marker-assisted selection of Pm21 gene conferring resistance to powdery mildew in wheat. J. Genet. Genomics 26:673-682.

Luo, P., Hu, X., Chang, Z., Zhang, M., Zhang, H., and Ren, Z. 2009. A new stripe rust resistance gene transferred from Thinopyrum intermedium to hexaploid wheat (Triticum aestivum). Phytoprotection 90:57-63.

Ma, J., Zhou, R., Dong, Y., and Jia, J. 1999. Chromosomal location of yellow rust resistance gene(s) in Triticum aestivum-Lophopyrum elongatum substitution lines. Chin. Sci. Bull. 44:344-348.
Mago, R., Miah, H., Lawrence, G. J., Wellings, C. R., Spielmeyer, W., Bariana, H. S., Mcintosh, R. A., Pryor, A. J., and Ellis, J. G. 2005. High-resolution mapping and mutation analysis separate the rust resistance genes $\mathrm{Sr} 31$, Lr26 and $Y r 9$ on the short arm of rye chromosome 1. Theor. Appl. Genet. 112:41-50.

McIntosh, R., Mu, J. M., Han, D. J., and Kang, Z. S. 2018. Wheat stripe rust resistance gene $Y r 24 / Y r 26$ : A retrospective review. Crop J. 6:321-329.

McIntosh, R. A., Dubcovsky, J., Rogers, W. J., Morris, C., Appels, R., and Xia, X. C. 2016. Catalogue of Gene Symbols for Wheat: 2016 Supplement. https://shigen.nig.ac.jp/wheat/komugi/genes/macgene/supplement2015.pdf

McIntosh, R. A., Dubcovsky, J., Rogers, W. J., Morris, C., Appels, R., and Xia, X. C. 2017. Catalogue of Gene Symbols for Wheat: 2017 Supplement. https://shigen.nig.ac.jp/wheat/komugi/genes/macgene/supplement2017.pdf

Robert, O., Abelard, C., and Dedryver, F. 1999. Identification of molecular markers for the detection of the yellow rust resistance gene $\mathrm{Yr} 17$ in wheat. Mol. Breed. 5:167-175.

Sardesai, N., Kumar, A., Rajyashri, K., Nair, S., and Mohan, M. 2002. Identification and mapping of an AFLP marker linked to $\mathrm{Gm} 7$, a gall midge resistance gene and its conversion to a SCAR marker for its utility in marker aided selection in rice. Theor. Appl. Genet. 105:691-698.

Song, W., Xie, H., Liu, Q., Xie, C. J., Ni, Z. F., Yang, T., Sun, Q. X., and Liu, Z. Y. 2007. Molecular identification of $P m 12$-carrying introgression lines in wheat using genomic and EST-SSR markers. Euphytica 158:95-102.

Tang, X. Q., Shi, D., Xu, J., Li, Y. L., Li, W. J., Ren, Z. L., and Fu, T. H. 2014 Molecular cytogenetic characteristics of a translocation line between common wheat and Thinopyrum intermedium with resistance to powdery mildew. Euphytica 197:201-210.

Tian, C., Lu, Y. F., Deng, J. X., Li, B., Zhang, X. Y., and Liu, G. T. 2000 Microdissection of additional chromosome in common wheat-Th intermedium TAI-27 and screening of its special probe. Sci. China Ser. C Life Sci. 43:105-112.

Wan, C. Y., Ji, W. Q., Xue, X. Z., and Wang, Q. Y. 1999. Studies on yellow rust resistance of T. aestivum Th. intermedium alien disomic addition lines. Acta Bot. Boreal Occident. Sin. 19:54-58

Wellings, C. R. 2011. Global status of stripe rust: A review of historical and current threats. Euphytica 179:129-141.

Wetzel, J.B., and Rayburn, A.L. 2000. Use of fluorescence genomic in situ hybridization (GISH) to detect the presence of alien chromatin in wheat lines differing in nuclear DNA content. Cytom. Part B Clin. Cy. 41:36-40.

Wu, J. H., Huang, S., Zeng, Q. D., Liu, S. J., Wang, Q. L., Mu, J. M., Yu, S. Z., Han, D. J., and Kang, Z. S. 2018a. Comparative genome-wide mapping versus extreme pool-genotyping and development of diagnostic SNP markers linked to QTL for adult plant resistance to stripe rust in common wheat. Theor. Appl. Genet. 131:1777-1792.

Wu, J. H., Liu, S. J., Wang, Q. L., Zeng, Q. D., Mu, J. M., Huang, S., Yu, S. Z., Han, D. J., and Kang, Z. S. 2018b. Rapid identification of an adult plant stripe rust resistance gene in hexaploid wheat by high-throughput SNP array genotyping of pooled extremes. Theor. Appl. Genet. 131:43-58.

Xie, W. L., Ben-David, R., Zeng, B., Dinoor, A., Xie, C. J., Sun, Q. X., Röder, M. S., Fahoum, A., and Fahima, T. 2012. Suppressed recombination rate in 6VS/6AL translocation region carrying the $P m 21$ locus introgressed from Haynaldia villosa into hexaploid wheat. Mol. Breed. 29:399-412.

Xin, Z. Y., Zhang, Z. Y., Chen, X., Lin, Z. S., Ma, Y. Z., Xu, H. J., Banks, P. M., and Larkin, P. J. 2001. Development and characterization of common wheatThinopyrum intermedium translocation lines with resistance to barley yellow dwarf virus. Euphytica 119:163-167.

Yang, L. J., Zhang, X. J., Zhang, X., Wang, J. R., Luo, M. C., Yang, M. J., Wang, H., Xiang, L. B., Zeng, F. S., Yu, D. Z., Fu, D. L., and Rosewarne, G. M. 2017 Identification and evaluation of resistance to powdery mildew and yellow rust in a wheat mapping population. PLoS One 12:e0177905

Yang, Z. J., Li, G. R., Chang, Z. J., Zhou, Z. P., and Ren, Z. L. $2006 a$ Characterization of a partial amphiploid between Triticum aestivum cv. Chinese Spring and Thinopyrum intermedium ssp. trichophorum. Euphytica 149:11-17.

Yang, Z. J., Liu, C., Feng, J., Li, G. R., Zhou, J. P., Deng, K. J., and Ren, Z. L. 2006b. Studies on genome relationship and species-specific PCR marker for Dasypyrum breviaristatum in Triticeae. Hereditas 143:47-54.

Zhan, H. X., Zhang, X. J., Li, G. R., Pan, Z. H., Hu, J., Li, X., Qiao, L. Y., Jia, J. Q., Guo, H. J., Chang, Z. J., and Yang, Z. J. 2015. Molecular characterization of a new wheat-Thinopyrum intermedium translocation line with resistance to powdery mildew and stripe rust. Int. J. Mol. Sci. 16:2162-2173.

Zhang, H. Z., Xie, J. Z., Chen, Y. X., Liu, X., Wang, Y., Yan, S. H., Yang, Z. S., Zhao, H., Wang, X. C., Jia, L. H., Cao, T. J., and Liu, Z. Y. 2017a. Mapping stripe rust resistance gene $\operatorname{YrZM103}$ in wheat cultivar Zhengmai 103 by BSR-Seq. Acta Agron. Sin. 43:1643.

Zhang, X. D., Wei, X., Xiao, J., Yuan, C. X., Wu, Y. F., Cao, A. Z., Xing, L. P., Chen, P. D., Zhang, S. Z., Wang, X. U., and Wang, H. Y. 2017b. Whole genome development of intron targeting (IT) markers specific for Dasypyrum villosum chromosomes based on next-generation sequencing technology. Mol. Breed. 37:115.

Zhao, J. J., Qiao, L., Zheng, X. W., Li, X. H., Cao, Y., Ma, X. F., Yang, B., Ji, H. T., Qiao, L. Y., Zheng, J., and Zhang, J. C. 2018. Variation of qualityrelated traits and HMW-GS of wheat cultivars in Shanxi province. Plant Genet. Resour. 19:1126-1137. 